Case Report

\title{
AUTOMMUNE HAEM OLYTIC ANEMIA : A REPORT OF TWO CASES
}

\author{
Chandrika Rao ${ }^{1} \&$ Jayaprakash Shetty ${ }^{2}$ \\ ${ }^{1}$ Assistant Professor \& Blood Bank Officer, ${ }^{2}$ Professor \& HOD, Department of Pathology \\ K.S. Hegde M edical Academy, Nitte University, M angalore, Karnataka, India. \\ Correspondence : \\ Chandrika Rao \\ Assistant Professor \& Blood Bank Officer Department of Pathology, K.S. Hegde M edical Academy, \\ Nitte University, M angalore - 575 018, Karnataka, India. \\ E-mail : chandrika_valal@yahoo.com
}

\section{Abstract :}

Autoimmune hemolytic anaemia (AIHA) is rare clinical disorder and requires efficient immunohematological and transfusion support. We report two cases of Immune hemolytic anaemia. A case of AlHA in congestive cardiac failure and second a known case of Giant cell arteritis with cold antibodies. Both the cases we encountered problems during cross matching.

Keywords : AlHA, Blood transfusion, direct antiglobulin test, autoantibodies

\section{Introduction :}

Immune hemolytic anaemia (IHA) is the clinical condition in which antibodies of immunoglobulin G (IgG) and / or immunoglobulin $M(\operatorname{lgM})$ bind to red cell surface antigens and initiate red cell destruction via complement system and reticuloendothelial system. [1] Immune hemolysis is a shortening of red blood cell survival due directly or indirectly to antibodies. [2] It is necessary to identify these irregular antibodies in patient serum in order to select appropriate blood for transfusion. Even in the most vexing situation encountered, where no compatible blood units are available for patient with severe anemia, transfusion should not be denied.

\section{Case 1:}

A 15 years old female presented with complaints of cough of one month duration associated with fever and vomiting of two weeks duration. On examination there was tachycardia, severe pallor with icterus. Systemic examination showed firm hepatomegaly and splenomegaly. Complete Access this article online Quick Response Code

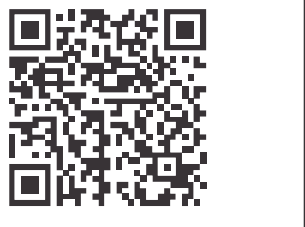
hemogram revealed markedly reduced haemoglobin $(2.9 \mathrm{gm} / \mathrm{dl})$, ESR was raised (160mm/hr), low platelet count and high red cell indices. Reticulocyte count was $6 \%$ and negative for malarial parasite. Blood smear showed haemolytic anaemia with thrombocytopenia. Bone marrow examination revealed erythroid hyperplasia. Liver function test showed high bilirubin levels. ANA and dsDNA were within normal range. A Vitamin B12 level was reduced. Direct coombs test was strongly positive with polyspecific AHG plus monoclonal C3d. Diagnosis of autoimmune haemolytic anaemia with congestive cardiac failure was made. Transfusion was requested but cross match was incompatible. Two units of least incompatible (best matched) packed red cells were transfused. Her haemoglobin was raised to $8.8 \mathrm{gm} / \mathrm{dl}$ during her hospital stay. Her clinical condition improved and she was discharged with an advice to follow up.

\section{Case 2:}

A 56years old female was referred to our hospital with complaints of giddiness of one month duration and history of transient loss of vision mainly in the right eye. She had similar complaint one year back and was diagnosed as a case of Giant cell arteritis and wastreated with steroids. On general physical examination there was pallor and mild pedal oedema. Systemic examination within normal limits. Hematological examination revealed moderate anaemia (Hemoglobin - 6.3gm/dl), markedly elevated ESR $(135 \mathrm{~mm} / \mathrm{hr})$ and reticulocyte count of $10 \%$. Peripheral blood smear showed agglutination of red cells, polychromasia, and anemia. Erythroid hyperplasia was 
noted in bonemarrow. Blood urea, creatinine, and liver function tests were within normal limits. ANA and anti-ds DNA were within normal reference range. The patient's sample was received in the blood bank for cross matching. Cell and serum grouping showed discrepancy. Patient was typed as 0 Rh positive. Direct antiglobulin test with polyspecific AHG plus monoclonal anti C3d was strongly positive. Blood transfusion was requested and cross match was incompatible. One unit of 0 positive least incompatible packed red cell was transfused without any adverse reactions. Biopsy of superficial temporal artery showed features consistent with Arteritis. Her clinical condition improved and she was discharged from hospital.

\section{Discussion :}

Autoimmune haemolytic anemia (AlHA) is rare. Correct diagnosis is dependent on proper comprehension of the pathophysiology and laboratory tests performed by the transfusion laboratory. [3]

Warm autoantibodies are responsible for $48-70 \%$ of AlHA cases. $[1,2,4,5]$ Positive direct antiglobulin test may be the first serological evidence. Anemia is of variable severity and some patients present with fulminant hemolysis, jaundice, pallor, hemoglobinuria and hepatosplenomegaly. $[3,6]$

In the first case, patient presented with severe anaemia, jaundice, mild hepatosplenomegaly and evidence of hemolysis. The direct coombs test was positive. Our patient had received "least incompatible" transfusion, due to severe anaemia with imminent clinical deterioration. When decision to transfuse mismatched blood is taken, transfusion of small aliquots to provide relief of symptoms and avoid fluid overload has been recommended. [2, 7] Leukoreduced blood products and premedication with antihistamines and antipyretics to prevent febrile and allergic reactions are recommended in patients with multiple antibodies. $[2,8]$

The second patient was a rare case of Giant cell arteritis, with cold antibodies presented with history of giddiness and transient loss of vision, high ESR, low haemoglobin, evidence of hemolysis in blood smear and autoagglutination. The occurrence of cold antibodies in arteritis suggest disordered plasmaprotein metabolism and a relationship to certain condition in which dysgloblinaemia occurs: polyarterits nodosa, rheumatoid arthritis, rheumatic fever and lupus erythematosus.[9] Instances of Giant cell arterits have shown disorders of plasma protein metabolism. Small and Gavrilesen (1963) found elevated alpha 2 glycoprotein with marked elevation of alpha 2 globulins and slight elevation of gamma globulins. [9] These abnormalities were corrected by adrenal steroid therapy. Whitfield, Meynell, Fessy and Hudson (1962) described a patient with Giant cell arteritis in who there was circulating factor VIII inhibitor which disappeared on steroid therapy. [9] Further, elucidation of the relationship of various forms of vasculitis to the dysglobulinaemias may appear with more complete plasma protein analysis in patients with these disorders. [9]

In context to Indian scenario Das et al opined that decision to transfuse in AlHA should be based on the clinical condition of the patient.[1,10] No critical patient should be denied blood transfusion due to serologic incompatibility.[1]Transfusion must be performed under control of vital parameters, such as cardiac function (ECG), renal function and diuresis. If there is no vital indication for transfusion it is prudent to wait for the results of immunohematological tests and ensuing transfusion advice based on this. [3]

Corticosteroid therapy is the mainstay of treatment in AlHA. Transfusion is of transient benefit but may be required initially because of severity of anaemia. Transfusion of red cells in AlHA can be complicated because of cross matching problems and rapid in vivo destruction of transfused cells due to the presence of autoantibodies. [11-14] immunosuppressive agents including monoclonal anti-CD20 (Rituximab) may prove useful in AlHA. Splenectomy is of benefit in refractory cases. [11]

In conclusion, a good communication must be established between the clinician and the transfusion specialist to assess the clinical urgency and the complexity of the 
serological studies. The final decision to transfuse should depend on the evaluation of the patient's clinical status

\section{References:}

1. Chaudhary RK, Das SS. Autoimmune haemolytic anemia: From lab to bedside. Asian J Transfusion Science 2014; 8:5-11.

2. Kaur P, Basu S, Kaur R, Kaur G. Immune haemolytic anemia: A report of two cases. J Laboratory Physicians 2009;1:22-4.

3. Zeerleder S. Autoimmune haemolytic anaemia - A practical guide to cope with a diagnostic and therapeutic challenge. The Netherlands J Med 2011;69:177-84.

4. Sokol RJ, Hewitt S, Stamps BK. Autoimmune hemolysis: an 18 year study of 865 cases referred to a regional transfusion centre. Br Med J 1981;282:2023-7.

5. Petz LD, Garraty G. Acquired immune haemolytic anemias. New York: Churchill Livingstone; 1980

6. Gehrs BC, Friedberg RC. Autoimmune haemolytic anaemia. Am Hematol 2002;69:258-71.

7. Ness PM. How do I encourage clinicians to transfuse mismatched blood in patients with autoimmune haemolytic anaemia in urgent situations? Transfusion 2006:46:1859-62.

8. Meny G. Review: Transfusing incompatible RBC's - clinical aspects and the benefits must be weighed to the potential risks of transfusion.

Immunohemat 2004:20:161-6.

9. Flanagan P, M cCracken AW, Jones FR, Cross RM . Necrotizing arteritis with giant cells associated with haemolytic anaemia. J Clin Path 1965:18:588-92.

10. Das SS, Chaudhary R. Transfusion support in autoimmune haemolytic anemia. Indian J Hematol Blood Transfus 2006;1:9-13.

11. Reddy VRS, Samayam P, Ravichander B, Bai U. Autoimmune haemolytic anemia: Mixed type - A case report. Indian J Hematol Blood Transfus 2011:27;107-10.

12. Shetty SK, Joshi SS, Shenoy VM, Shetty SB. Autoimmune haemolytic anemia: an interesting presentation and review of literature. Int J Biomed Res 2013:4:355-56.

13. Park D, Yang C, Kim K. Autoimmune haemolytic anemia in children Yonsei M edJ 1987;28:313-21.

14. Sutaone B, Jain N, Mathur NB, Khalil A. Blood transfusion in autoimmune haemolytic anemia: a practical problem. Indian Pediatr 1993:30:264-66. 